\title{
THE FORMATION OF PRODUCT SAFETY WITHIN STOCK MOVEMENT
}

\author{
Datchenko Anastasiya, ${ }^{*}$ Gissin Vitaly \\ Rostov State University of Economics, Rostov-on-Don, Russian Federation
}

\begin{abstract}
Product safety and quality are among the key indicators that determine the company's efficiency in modern economics. Changes in state economics and policy such as Russia's accession to the WTO and its functioning within the Customs Union force domestic manufacturers to take a fresh look at these issues. Logistic concept of quality and safety involves application of logistic principles and methods for the quality and safety management on one hand, and forming of related organization's system and appropriate control measures for the quality and safety as a control object on the other. Thus, this concept should naturally combine logistics and security. Effective implementation of legal framework on the part of manufacturers and competent authority's control on its observance may provide a stream of safe and quality products coming to mass retailers, which significantly reduces the cases of food poisoning.
\end{abstract}

Keywords: food security, supply chains, logistics, standards

\section{Introduction}

Ecological environment, common morality, quality and food safety are among the most important factors affecting the health of population and, therefore, determining the quality of human life. Healthy and quality nutrition is an issue depending on production, distribution and sales solutions taken by numerous partners.

Recently, international and domestic trade have paid a lot of attention to two key indicators - safety and reliability, which should be constantly monitored and analyzed in order to provide efficient operation of supply chains' processes, representing a system of processes, resulting in transportation of raw materials and goods from the place of manufacture to the receiving point.

This system includes a number of entities, i.e. manufacturers, logistic service providers, sea-, road-, train-, and air carriers, customs, financial and information intermediaries, and consumers as well.

Supply Chain is a complex system within commercial activity, consisting of numerous processes of different size and importance (Surzhikov, 2010). Therefore, according to the principles of international standards ISO 9000 (GOST ISO 9000-2011, GOST ISO 9001-2011), the supply chain can be considered as a range of processes, fulfilling a transformation of input parameters into result. In other words, trading activity can be defined as a chain of interconnected processes, in which the yield of the previous process results in input of the next one. The yield appears to be the result of input streams' conversion.

It should be noted that within trading activities, results may or may not correspond to requirements, or may contain temporary financial information on process. Effective process structure results in added value, including profit, increase in sales and quality indicators.

\section{Material and methods}

Product and service quality, reactivity and flexibility of assorted customer needs, optimal costs, reliability and security of supply, high-grade implementation and distribution processes' service appear to be important competitive factors within recent market economy.
Manufacturers and companies that are not able to promptly fit themselves into changing market conditions should be aware that it can lead to serious problems of long-term competition. For this reason, market participants need to pay more attention to the safety of work as well as distribution at all stages of logistic system processes.

The requirements for products entering the Russian market from foreign partners have recently tightened. In some cases, goods are not allowed to enter the market due to violations in safety indicators. Thus, in 2013 the head of Rospotrebnadzor (Federal Service for Supervision of Consumer Rights Protection and Human Welfare) suspended the import of milk products from Lithuania as a result of quality violations, and pathogens found in these products, in particular. In 2012, a number of Ukrainian cheese producers were banned from goods distribution in Russia due to violation of Russian technical regulations on milk and dairy products. These examples show the attitude of government and business to safety problems.

There are different types of safety in logistic systems, i.e. mechanical, chemical, biological, transport. They all depend on conditions of goods formation within products' manufacturing, delivery, distribution and sales.

Each stock movement stage solves the problem of safety in its own way.

For example, manufacturers are obliged to carry out production (manufacturing) so that products meet the requirements set by technical regulations. While implementing production (manufacturing) of foods related with safety requirements of such products, a manufacturer should design, introduce and maintain procedures based on HACCP principles and provided by technical regulations of the Customs Union.

The functioning of HACCP system within food safety field is based on the general methodology of seven quality management principles.

Current regulations of the Russian Federation are used to ensure security at "delivery of products" stage (TR CU 021/2011, GOST R 536632009) that is particularly important to international supply chains. These regulations specify the requirements that allow any organization, entering the supply chain, to install, maintain and improve the safety management system, including aspects that are crucial to guarantee the reliability of this chain. 
Safety of goods within distribution and sales is achieved by following the requirements of technical regulations and specifications, sanitary standards on processes, equipment, personnel, and the use of HACCP.

In order to define the effectiveness of current logistic systems related to security of perishable products supply, we made a reverse audit of stock products' quality and safety.

In order to identify the safety of stock movement within logistic system, one type of perishable products was taken as an object of study. The research on this item produced by different manufacturers and acquired in five selling spots of Rostov-on-Don, was carried out with the use of various methods, i. e. organoleptic, physicochemical and microbiological.

\section{Results and Discussion}

The studies have shown the following results:

$\square \quad 20 \%$ of items fit the organoleptic standard requirements;

$\square \quad 40 \%$ of items do not fit the physicochemical standard requirements; $\square 100 \%$ of items do not fit microbiological safety requirements.

The reason of revealed inconsistencies lies in the lack of proper control on the last link of goods movement that is a process of implementation. The research revealed the absence of products technical specifications, disregard for rules in accordance with the standards and regulations (GOST R ISO 22000-2007, TR CU 021/2011).

The studies led us to the following conclusion: effective instruments should be used in all parts of logistic system in order to ensure the safety of production, distribution, and sale processes. Hazard Analysis and Critical Control Points safety system may serve as one of the effective instruments. Security of supply chains, both in domestic and international trade, requires the implementation of standards.

Implementation phase requires the observance of current technical specifications, regulations or standards of security.

It is noted that currently there is no management mechanism for perishable products' movement, meeting the requirements of market economic system at all stages of the life cycle.

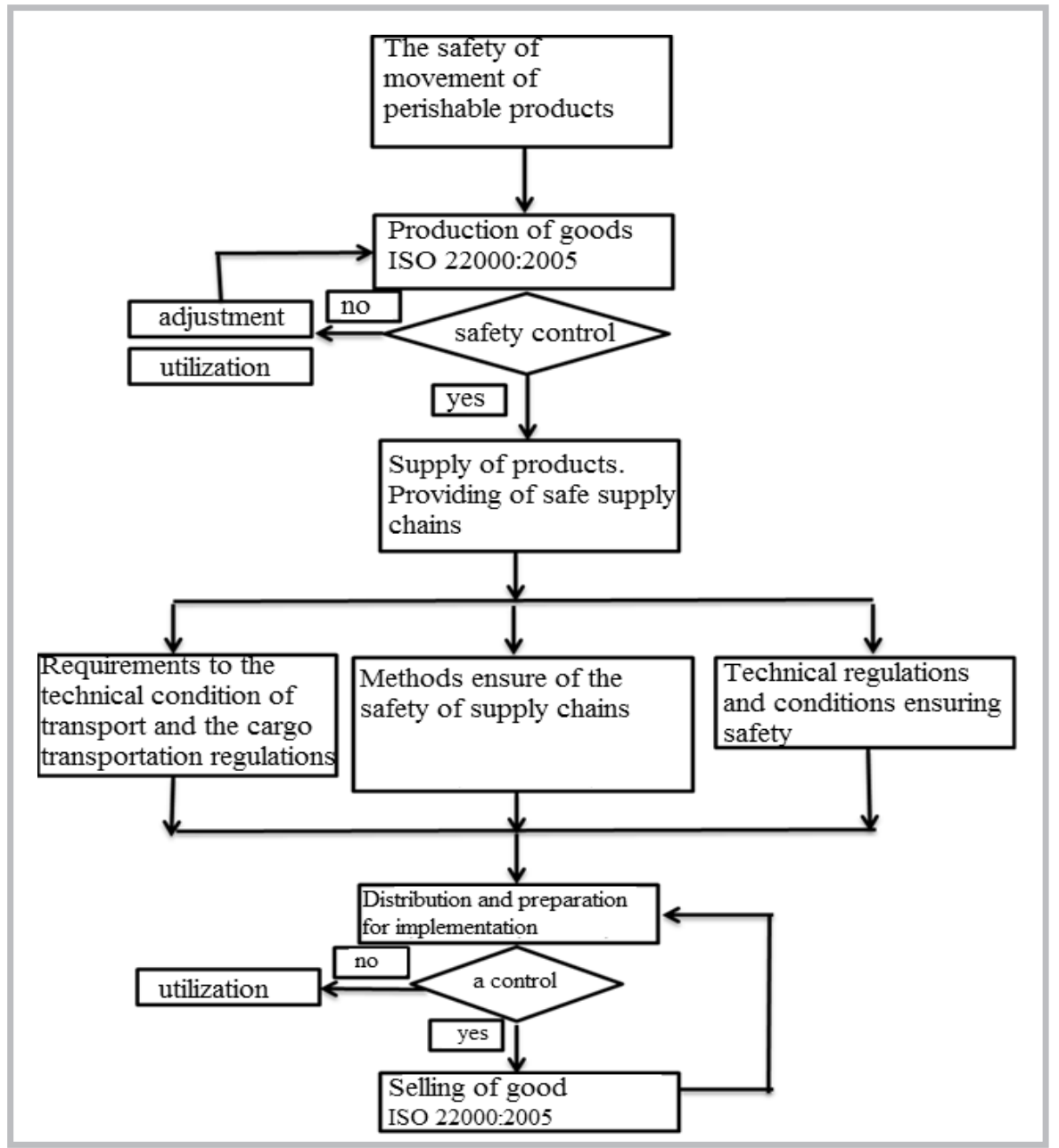

Figure 1 Comprehensive system of measures to ensure supply safety

The essential conditions to define the efficiency of perishable products movement are reliability, safety and compliance with the necessary sanitary and technological standards throughout the supply chain that allow maintaining the quality of the product and its safety for the consumer. Thus, to improve the efficiency of the delivery process it is necessary to use solutions that can ensure the security of perishable products supply within logistic system, consisting of production merchandising - distribution - realization.

In order to ensure the efficient operation of the whole logistic system, we recommend using a set of measures (Figure 1) on the perishable products supply security.

Figure 1 clearly shows that the safety of perishable goods movement is affected by various reasons, such as production process safety conditions, product delivery, its distribution and implementation.

All participants of stock movement should base upon current regulatory requirements, regulations, standards, technical specifications, as their implementation will allow the organizations, involved in perishable products supply chain, to install, maintain and improve the safety management system in production, transportation, distribution and selling.

For the foregoing reasons, we conclude that constant management of production, supply chain and sales should be conducted in order to ensure the safety of supply chains.

\section{References}

GOST R ISO 22000:2007 „Food safety management systems. Requirements for any organization in the food chain".

GOST ISO 9001:2011 Quality management systems. Requirements.

GOST ISO 9000:2011 Quality management systems. Fundamentals and vocabulary.

SURZHIKOV, M. 2010. Foreign Trade: Issues of quality management: scientific and practical guide; Rostov State University of Economics (RSUE). Rostov-onDon, 2010. P.71.

TR CU 021/2011, Safety of food products".

\section{Contact addresses}

*Datchenko Anastasiya, Rostov State University of Economics (RINH), telephone number 8 (863) 240-58-40, 69, Bolshaya Sadovaya Street, Rostov-on-Don, Russian Federation, e-mail: allworldforme@mail.ru 